\title{
Design and Process control of Siemens Poly- silicon CVD Reactor
}

\author{
${ }^{1}$ A.Swetha Priya, ${ }^{2}$ S.Vinod Kumar, ${ }^{3}$ Sibin K.Mathew and ${ }^{4}$ Abhinav A.Kalamdani \\ ${ }^{1}$ Tessolve Semiconductors, ${ }^{2}$ Robert Bosch, ${ }^{3}$ National Aerospace Lab.(NAL) Bangalore, India \\ ${ }^{4}$ Sunlux Technologies Ltd., Photovoltaics and Controls,Bangalore, India
}

\begin{abstract}
The novelty in this paper is to develop a process control for the poly-silicon CVD reactor to achieve optimum productivity of Poly-silicon seed by controlling the process parameters. The production of ingot is done through Siemens process of decomposing Trichlorosilane by Chemical Vapor Deposition on slim tungsten rods. The hardware architecture proposed monitors and controls the systematic sequential stages furnishing dynamics of the plant at a high temperature around $1050^{\circ} \mathrm{C}-1100^{\circ} \mathrm{C}$. The HMI communicates through NI's LabVIEW 8.6 package, alarming the user with Process mimic, Report generation, Data and Security management. The plant simulation is realized and verified with LabVIEW 8.6 Version and MATLab 7.5 software tools to obtain the effectiveness of proposed control technique. This GUI based SCADA handles likelihood of fault tolerance, ensuring risk controlled process with optimum productivity of poly-silicon by making system compliant to Industrial standards.
\end{abstract}

Keywords-Chemical Vapor Deposition(CVD), Human Machine Interface(HMI), Siemens process, Solar-grade silicon.

\section{INTRODUCTION}

Awareness of the need to reduce $\mathrm{CO}_{2}$ emission has only added to the mandate for renewable energy. This public awareness for higher energy prices and global warming problem has opened up the market for solar cell, demanding for energy supply [1]. So have the efforts to make renewable sources as fundamental part of sustained development strategy reinforcing the concern for tight raw material supply of poly-silicon, for two reasons: (1) the scarcity of silicon ingot in the world and (2) India importing SOG-Si (Solargrade silicon). This brought the surge to conserve energy with a tight raw material supply of poly-silicon ingot, giving an impetus to rapid development of solar cell manufacturing industries to expand large-scale production of Poly-silicon vigorously involving new processing techniques [2-4]. This motivated us to focus towards the development of a process control for Poly-silicon CVD reactor, in this paper, which is mainly aimed to expand silicon reproducible plants in India and to achieve optimized productivity of poly-silicon seed through Siemens process utilizing optimum resources with a vital look on reliable test systems designed for the control of risk process parameters.

The production routes of polycrystalline or solar-grade silicon are of two categories: 1) Chemical route and 2) Metallurgical route. Chemical route is preferred for this proposed siemens model to obtain the purity level extended upto $10 \mathrm{~N}$ i.e., $99.99999999998 \%$. Siemens process consists of decomposing Tricholorosilane(TCS) by Chemical Vapor Deposition (CVD) on inverse U-shaped hair pin like hot tungsten filaments in a large water-cooled steel bell jar reactor [5],[6]. Architecture of CVD Reactor is illustrated with process stages in Section II. Section III descries the challenges faced during the development phase of poly-silicon crystal. Section IV illustrates PHA studies to overcome challenges posed by CVD Reactor and also describes capability to handle emergency conditions by making the system compliant with required industrial standards. Section $\mathrm{V}$ gives the hardware simulation and its results and section VI presents the conclusion and future work.

\section{ARChitecture OF POLY-Silicon CVD REACtOR}

The proposed hardware architecture for monitoring and control of the sequential processes of poly-silicon CVD reactor is depicted in the Fig. 1.

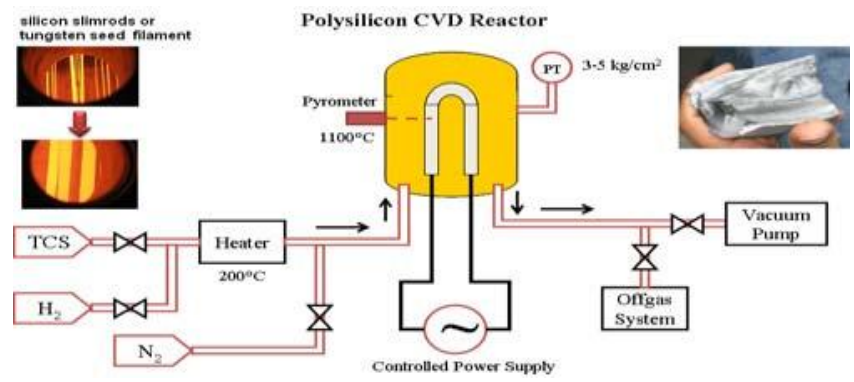

Fig. 1. Block diagram of poly -silicon CVD reactor [7], [8]

In the reactor, a constant rate of hydrogen gas is fed with maintained flow rate of TCS gas from lower to upper portions of the tube giving rise to the following chemical reaction.

$\left(1050^{\circ} \mathrm{C}-1100^{\circ} \mathrm{C}\right)$

$$
\mathrm{H}_{2}+3 \mathrm{HSiCl}_{3} \longrightarrow 2 \mathrm{Si}+5 \mathrm{HCl}+\mathrm{SiCl}_{4}
$$

The hydrogen flow agitates leaving the deposition of polysilicon around the surface of tungsten increasing the diameter from 3 to $100 \mathrm{~mm}$ or $150 \mathrm{~mm}$. This continuous process of 4 to 5 days is powered with a distribution system, an incomer panel that supplies a 3 -phase $11 \mathrm{KV}$ mains which is stepped down to voltages of $100-300 \mathrm{~V}$ at $5000 \mathrm{~A}$ by an auto-main transformer with On-Load Tap Changer (OLTC). Thyristor controls the load power by varying the firing angle. The optional pyrometers placed around the reactor in three 
directions sense filament temperatures ranging from 600$1400^{\circ} \mathrm{C}$ and gives out $4-20 \mathrm{~mA}$ depending on the amount of glow on the filament. The Cooling water supply to the reactor jacket with flow switches fitted on water manifold reduces temperature of the reactor. Pressure transmitters of -1 to 10 $\mathrm{kg} / \mathrm{cm}^{2}$ are used to sense reactor pressure. Filaments heated upto $1050-1100^{\circ} \mathrm{c}$ face challenges posed by process parameters like temperature, pressure, vacuum \& gas flow rates and electrical parameters like voltage, current, reactive and active powers.

Two silane compounds (TCS \& STC) are intermediates in solar-grade silicon production process via chemical route. The Hydrochloric acid formed during the process is sent to a recycling chamber for conversion of TCS gas. Conversion efficiencies and Film morphology depends on operating conditions like source gas mixtures, pressure and reactor temperature. The uniformity in film is built with the increase in pressure with maintained gas flow ratios. Since the homogeneous gas chemical reactions of silane decrease the linearity, the application of feedback control technique is required. After a permissible growth of thickness about 100 or $150 \mathrm{~mm}$, the process is completed by slicing down the ingot to Polycrystalline silicon seeds.

\section{Challenges Of Semiconductor CVD ReActor}

The system is composed by developing the sequential stages of Reactor evacuation and Leak test, TCS and $\mathrm{H}_{2}$ gas feedrate schedule, Temperature control at around $1050^{\circ} \mathrm{C}$ $1100^{\circ} \mathrm{C}$ followed by shutdown process to obtain the sliced poly-silicon ingot. These sequential processes are done to protect against toxic, corrosive, highly volatile gases from escaping out of the reactor which causes irritation of skin and mucous membrane. Reactor Evacuation and Leak test is a startup test to evacuate air inside the reactor to create a vacuum of $10^{-5}$ torr, in order to avoid its flammable reaction and also to check reactor's leak free status. Feedrate scheduling is the main process followed by Temperature controlling stage. The thickness of the film deposited depends on the feed ratios of gases to achieve the optimized productivity. As feed rate increases, pressure increases giving rise to uniform distribution of gas. Therefore, gas feedrates are changed at different instants of time according to scheduled ratios to control the reaction rates and also to control the pressure inside the reactor. Thus, this continuous process demands a controlling system for complex thermodynamic reactions to take place at a high temperature with desired productivity. If the temperature decreases below the range, the reaction rate decreases which in turn decreases the rate of deposition of Poly-silicon. If the temperature increases above the range, surface of silicon and tungsten softens losing the stability causing a filament failure. Despite of this, the other challenges faced by the reactor are:

- It is Multi-Input Multi-Output(MIMO) system

- $\quad$ Thermally coupled filaments with radiation heat transfer.

- $\quad$ Continually increased diameter with thermal mass.

- $\quad$ Constantly changed gas mass and their ratios.

- Thermal runaway causes increase in current, increase in temperature $\&$ decrease in resistivity.

This developed CVD reactor acquired $10 \mathrm{~N}$ purity level with a vacuum evacuation reaching $10^{-5}$ torr followed by supervisory check list ensuring leak free reactor status. A closed loop control system ensured the flow of TCS \& $\mathrm{H}_{2}$ gas ratios as scheduled to achieve the required thermal kinetics at $1050^{\circ} \mathrm{C}-1100^{\circ} \mathrm{C}$. A state model is designed to realize the plant dynamics at different temperatures to obtain the transient and frequency response with respect to the plant dimensions. HMI designed handles and alarms the user regarding the likehood of fault tolerance and remedies to give a multi-layer protection to the events of siemens CVD system by making it compliant with required industrial standards. After permissible polysilicon growth, the process is shut down by reducing the temperature profile with the current profile down to zero with a change in feed rates. Thus, the developed control system ensured handling of emergencies with uniform poly-silicon growth and kinetics by controlling the process parameters.

\section{PRocess SAFEty \& EMERGENCY HaNDLING}

The process and Instrumentation dynamics are key considerations principled with multi-layered protection for system analysis [9],[10]. Each layer of protection consists of grouping an equipment and/or human activity which address an emergency situation to be informed to the community with an engineering approach to control hazard. This decision required for the measurement of Safety Instrumented System (SIS) performance is made acceptable with industrial standards to reach the assignment of target SIL (Safety Integrity Level) with the extension of Process Hazard Analysis (PHA) to mitigate risk associated with each level of CVD Reactor [11]. To establish a safe circuital operation of polysilicon CVD reactor, ANSI/ISA S5.1-1984(R1992) standard [12],[13] is used for design phase of the thermal plant for a quick and reliable information about process analysis and control of equipment requisites. The electrical design developed follows SEMI S22-0706a standard for safe operation [14]. IEC d61508 is taken as an umbrella standard for Industrial Electrical/Electronic \& Programmable Electronic Safety Related System (E/E/PE SRS) [15].

The objective of risk control in terms of likelihood and the severity of hazards were achieved qualitatively and quantitatively with PHA studies with assignment of Target SILs for SIF (Safety Instrumented Functions). Qualitative techniques namely HAZOP (Hazard and Operability) and FMECA (Failure mode, effects and criticality) analysis were adopted to identify failed events and made it capable against the hazardous consequence with remedy to safeguard the system [9]. The checklist verification tells the status of the equipments in order to avoid the hazards before the process starts. Power control \& Distribution panel failure (e.g., over current, under current, earth fault, ground fault and voltage fault protections), Air cooling failures, Over pressure and Instrumentation or Equipment failures like Heat exchanger, Valve, Rectifier, Pump failure (e.g., vacuum \& water), Autofocusing failure of Pyrometer and load failures are some failures which occurs posing challenge to the system. Certain factors like Power failure, Power blink, Instrument air/valve, Cooling water \& Load failures, Tube ruptures, Manual valve failure, Thermal run -away reactions, Breakage of Quartz window, Malfunction of Vacuum circuit breaker, Reactor leak 
and Communication failure causes emergency shutdown of the system [16], [17]. Human and In-process thorough monitoring around reactor vicinity reviews and ensures safety against fault occurrence through camera scanning. Quantitative risk analysis using Event tree technique helped in easy identification of hazards and risk associated in the process by suggesting suitable remedies for elimination.

The HMI is designed in NI's LabVIEW 8.6 package [18] for a user-friendly information exchange between man and machine. This HMI alarms for Emergency Off (EMO) operations with a programmed salience guiding the user to take appropriate action is complaint with SEMI E95-1101 Standard.

\section{Simulation Results Of CVD ReACtion}

The hardware simulation is developed using National Instrument LabVIEW8.6 Version (Laboratory Virtual Instrumentation Engineering Workbench) for visualizing the sequential plant process. The reactor evacuation and its status were realized with its ideal and practical characteristics as depicted in Fig. 2. Time required for evacuating air inside the reactor from an initial pressure $P_{i}$ to final pressure $P_{f}$ is estimated as [19].

$$
t=\left(\frac{v}{s}\right) \ln \left(\frac{p_{a}}{p_{f}}\right)
$$

Where $\mathrm{t}=$ Evacuation time $[\mathrm{hr}], \mathrm{S}=$ Average pump suction capacity $\left[\mathrm{m}^{3} / \mathrm{hr}\right], \mathrm{P}_{\mathrm{a}}=$ Atmospheric air inside the reactor at $\mathrm{t}_{\mathrm{o}}$ [torr], $\mathrm{P}_{\mathrm{f}}=$ Final pressure at $\mathrm{t}_{1}$ [torr], $\mathrm{d}=$ Diameter of the reactor, $\mathrm{h}=$ Height, $\mathrm{V}=$ System volume [m3]. The values in Table I are practical and real time values obtained during the test. This process is reviewed for 2 or 3 times, till the practical characteristics are identical to ideal characteristics reaching the minor leak check point reading $10^{-5}$ torr. If iterations prove that reactor is not leak free, jacket is substituted by another steel shield. Evacuation status and its progress with Process mimic, Observation table and Graph is shown in figures (Fig.3, Fig.4 \& Fig.5). After start-up stage is verified with leak test which is carried out with Nitrogen and Hydrogen flushing, the process starts with Feedrate scheduling. Both TCS and $\mathrm{H}_{2}$ gases are controlled by flow transmitters according to their feed schedule to maintain the pressure at 4-5 bars in the reactor. The outlet pressure valve is regulated accordingly to obtain characteristics as shown in figures (Fig.6 \& Fig.7).

TABLE I VALUE OF CHECK POINTS

\begin{tabular}{|c|c|}
\hline Control value opened & Ideal Characteristics \\
\hline Gross leak check point, $\mathrm{V}_{0}$ & $335.65 \mathrm{mtorr}$ \\
\hline Gross leak check time, $\mathrm{t}_{0}$ & $60 \mathrm{sec}$ \\
\hline Minor leak check point, $\mathrm{V}_{1}$ & $0.01 \mathrm{mtorr}(\mathrm{setpoint})$ \\
\hline Leak check start time, $\mathrm{t}_{1}$ & $756 \mathrm{sec}$ \\
\hline $\begin{array}{c}\text { Leak rate in vacuum, } \mathrm{dP} / \mathrm{dt} \\
\text { (Control valve closed) }\end{array}$ & $0.001 \mathrm{mtorr} / \mathrm{sec}$ \\
\hline Minor leak observation time $\mathrm{t}_{2}$ & $60 \mathrm{sec}$ \\
\hline
\end{tabular}

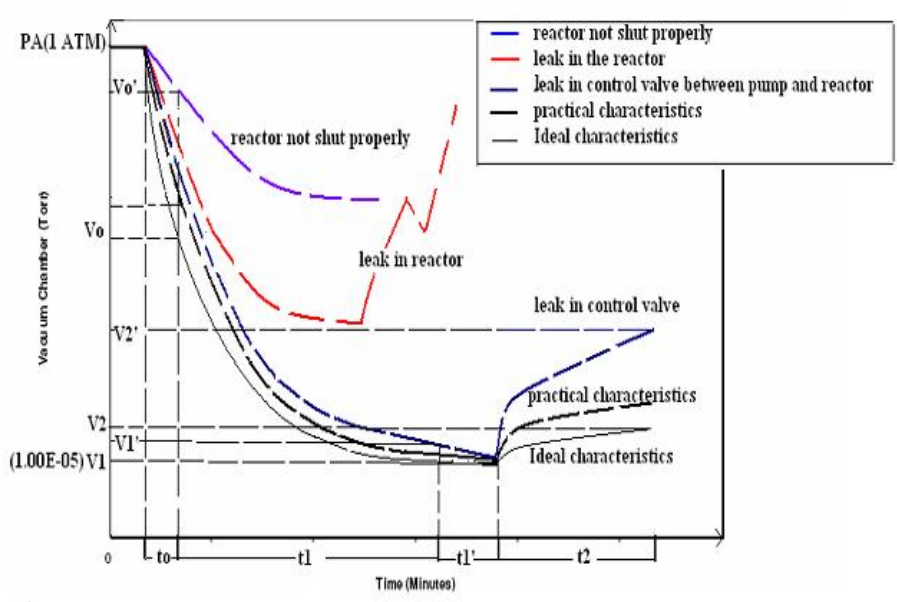

Fig. 2. Illustrates the characteristics of the Evacuation curve under different circumstances.

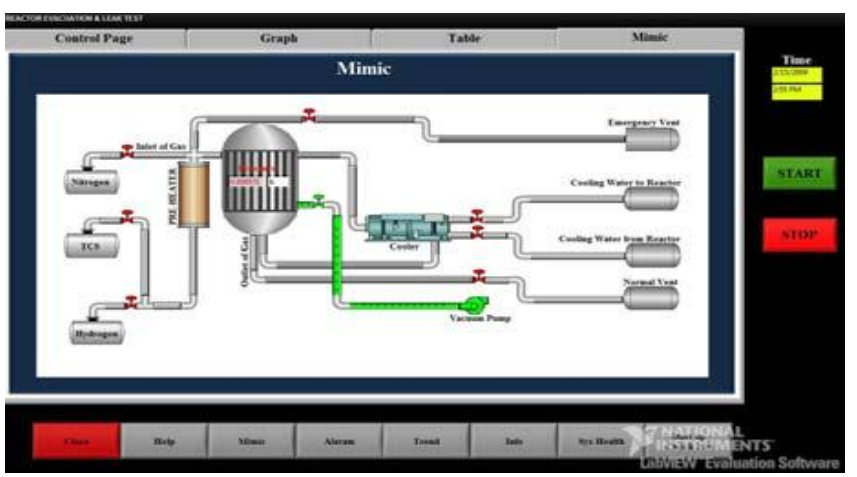

Fig. 3. Mimic page illustrating Evacuation test of reactor

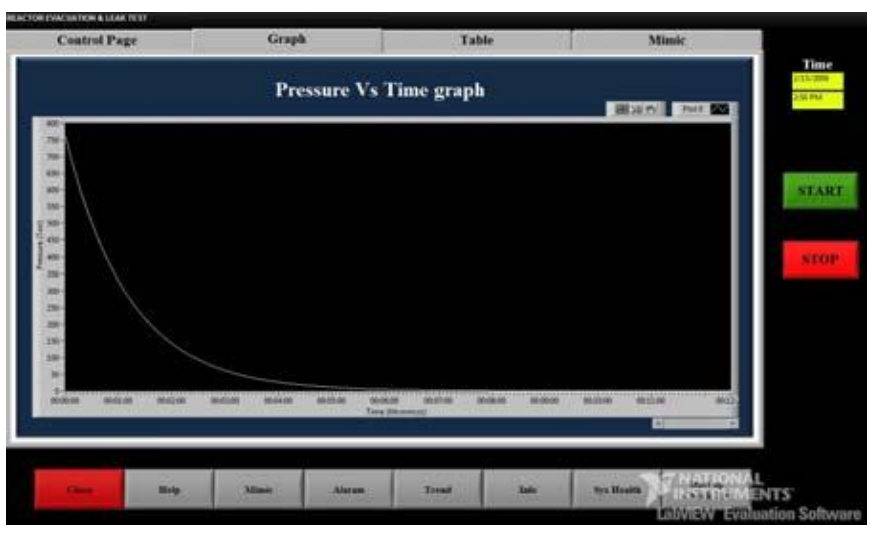

Fig. 4. Graph depicting Reactor Evacuation characteristics

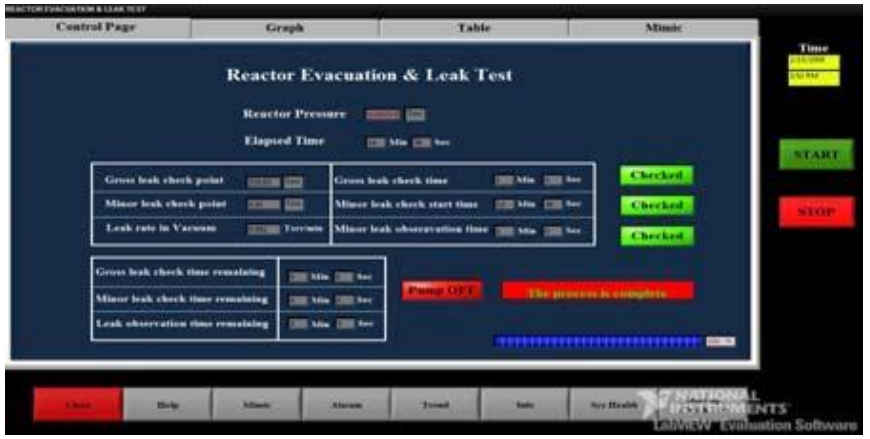

Fig. 5. Screen shot illustrating completion status of the process 


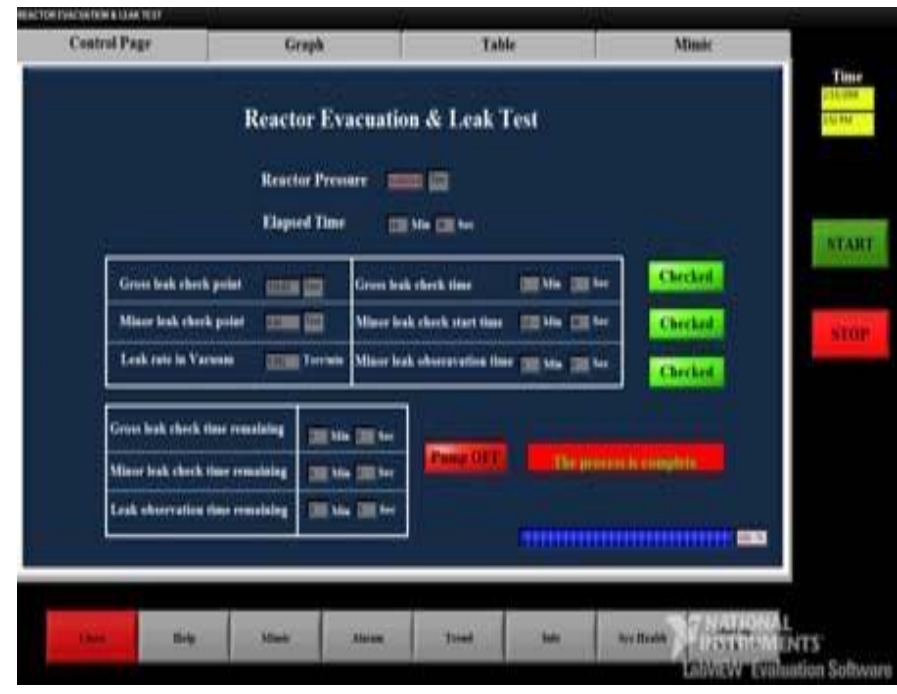

Fig. 6. Screen shot of mimic page for Feedrate scheduling

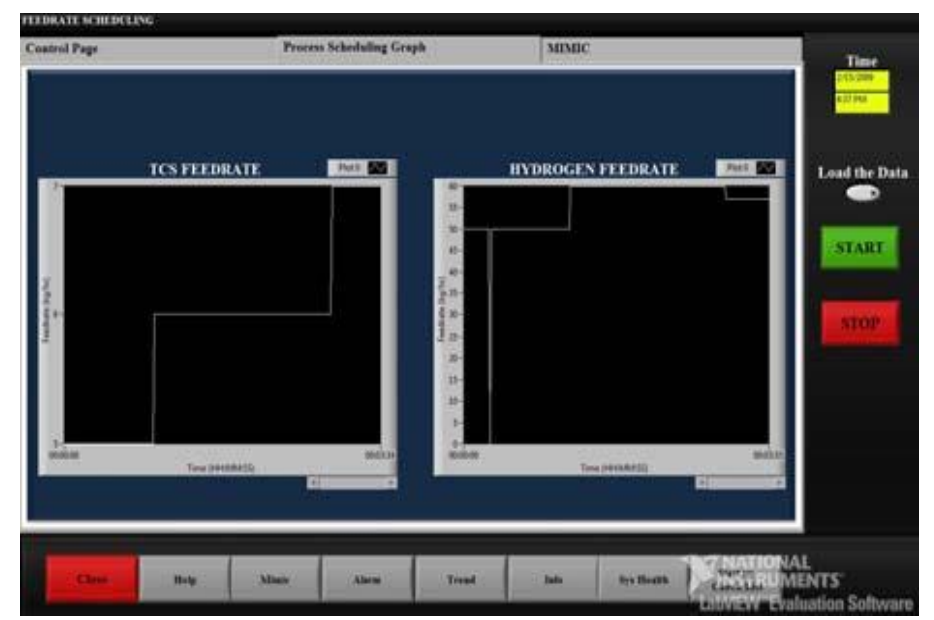

Fig. 7. Characteristics of TCS and Hydrogen feedrate as scheduled

The reactor vessel with slim tungsten rods are heated up through $230 \mathrm{~V}$ AC single phase power supply and the current required for heating is controlled with the help of Thyristor control panel. The model of cylinder is shown in Fig. 8. The cylindrical vessel of length (l) and diameter (d) is considered with inner radius of heater $r_{1}$, outer radius of cylinder $r_{2}$ and with an outer cover of radius $r_{3}$. It depends on the chemical composition of the cylinder like Tungsten, Nitrogen gas, Stainless steel and Glass boundaries. Heat flow in a radial direction is realized with its circuit model as shown in Fig.9. The system comprises an electrical heater of heat capacity $C_{h}$ connected via a thermal resistance $R_{h}$ to the furnace and to the surroundings with a thermal resistance of $R_{O}$ and with a heat capacity $C_{r}$. The filament kept at temperature $T_{h}$ transfers heat to surrounding air inside the furnace at temperature $T_{i}$, through the thermal resistance $R_{h}$. The heat flow in radial direction is exposed to two different temperatures $T_{i}$ at $900^{\circ} \mathrm{C}$ and $T_{o}$ at $1200^{\circ} \mathrm{C}$ making the model a linear time variant system. The increase in temperature will increase the pressure inside the closed radial reactor. Dynamics of the vessel at that particular time is modeled using state space realization following the conduction \& convection properties [23-26] and thermodynamic principles using following equations.

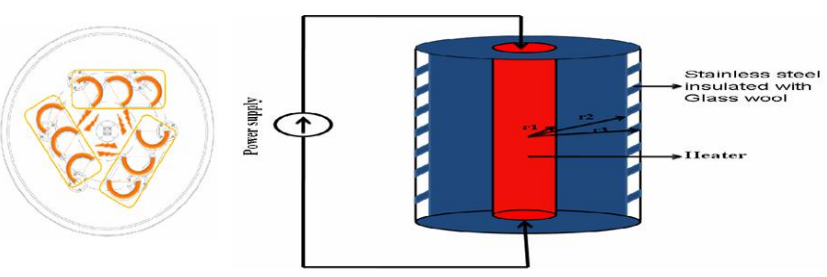

Fig. 8. Structure of the reactor with filaments

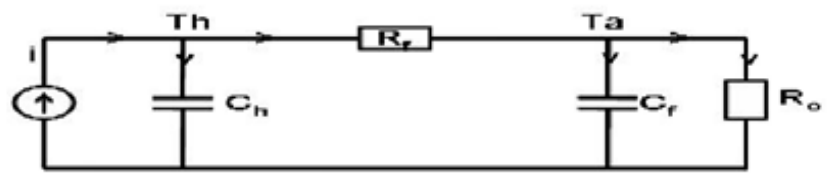

Fig. 9 Thermal model of the proposed reactor

Using Fourier's law [20-21], Heat flux of the radial system is given by $Q r=-k A r(d T / d r)$

where $A=2 \prod r^{2} l$, Area for heat flow in radial system. Heat conduction of the radial system at different temperatures is given by

$$
Q=2 \pi k l\left[\left(T_{h}-T_{a}\right) / \ln \left(r_{1} / r_{o}\right)\right]
$$

The thermal resistance is

$$
R_{t h}=\ln \left(\frac{r_{1}}{r_{o}}\right) /(2 \pi k l)
$$

Heat capacity is given by $(\Delta Q)=m * \mathrm{Cp}$

Where $\mathrm{m}$ is mass and $\mathrm{C}_{\mathrm{p}}$ is specific heat capacity at constant pressure. Using state model representation [22], we get

$$
\begin{gathered}
C_{a} \frac{d T_{a}}{d t}=\frac{1}{R_{f}} T_{h}-\left(\frac{1}{R_{o}}+\frac{1}{R_{f}}\right) T_{a} \\
T_{a}=\frac{1}{C_{h} R_{f}} T_{h}-\frac{1}{C_{h}}\left(\frac{1}{R_{o}}+\frac{1}{R_{f}}\right) T_{a}+(0) i
\end{gathered}
$$

Equations (6) \& (7) can be represented as

$$
\begin{gathered}
\left(\begin{array}{l}
T_{h} \\
T_{a}
\end{array}\right)=\left(\begin{array}{cc}
\frac{-1}{C_{h} R_{f}} & \frac{1}{C_{h} R_{f}} \\
\frac{1}{C_{f} R_{f}} & -\frac{1}{C_{h}}\left(\frac{1}{R_{o}}+\frac{1}{R_{f}}\right)
\end{array}\right)\left(\begin{array}{c}
T_{h} \\
T_{a}
\end{array}\right)+\left(\begin{array}{c}
\frac{1}{C_{h}} \\
0
\end{array}\right) i \\
T_{a}=\left(\begin{array}{ll}
0 & 1
\end{array}\right)\left(\begin{array}{l}
T_{h} \\
T_{a}
\end{array}\right)+(0) i
\end{gathered}
$$

A PID controller in feedback, controls the steady state and transient response as per the requirement. This controller provides the most accurate and stable control, and is best used in systems which react quickly to changes in the energy added to the process. Hence, setting the controller parameters is achieved by tuning it using cohen-coons method. Tuned parameters using the cohen-coons method are $T=250, t_{d}=$ $15 \mathrm{sec}, \mathrm{K}=1$. After tuning, 


$$
\begin{aligned}
& K_{c}=\frac{1}{k} \frac{\tau}{t_{d}}\left(\frac{4}{3}+\frac{t_{d}}{4 \tau}\right)=60 \\
& \tau_{1}=t_{d} \frac{32+6 \frac{t_{d}}{\tau}}{13+8 \frac{t_{d}}{\tau}}=0.1 \mathrm{Sec} \\
& \tau_{D}=t_{d} \frac{4}{11+2 \frac{t_{d}}{\tau}}=1200
\end{aligned}
$$

The process parameters are controlled and plant dynamics with its steady-state and frequency response are as shown in the screen shots of Fig.10, Fig.11 \& Fig.12. Practical and real time values obtained during the test is tabulated in Table II.

By adopting the state model, system is made completely observable, controllable and stable. This SCADA system (hardware and software) globally monitors and ensures user friendly process control interface with Real-time data trending along with Storage and easy retrieval of data, Report generation and delivers progress visualization of each level in the process. The diameter measurement is monitored and captured by a camera for a permissible growth of poly-silicon

\begin{tabular}{|c|c|c|c|c|}
\hline At $900^{\circ} \mathrm{C}$ & Tungsten & Glass wool & Hydrogen & Stainless steel \\
\hline Radius & $0.0015 \mathrm{~m}$ & $0.27 \mathrm{~m}$ & $0.15 \mathrm{~m}$ & $0.2 \mathrm{~m}$ \\
\hline Density & $\begin{array}{l}19300 \\
\mathrm{~kg} / \mathrm{m} 3\end{array}$ & - & $\begin{array}{c}0.06 \\
\mathrm{Kg} / \mathrm{m}^{3}\end{array}$ & - \\
\hline $\begin{array}{l}\text { Specific heat } \\
\text { capacity }\end{array}$ & $\begin{array}{c}150 \\
\mathrm{~J} /(\mathrm{Kg}-\mathrm{K})\end{array}$ & - & $\begin{array}{c}15150 \\
(\mathrm{~J} /(\mathrm{Kg}-\mathrm{k}))\end{array}$ & - \\
\hline Heat capacity & $\begin{array}{c}20.453 \\
(\mathrm{~J} / \mathrm{K})\end{array}$ & - & $\begin{array}{c}64.2208 \\
(\mathrm{~J} / \mathrm{K})\end{array}$ & - \\
\hline $\begin{array}{c}\text { Thermal } \\
\text { conductivity }\end{array}$ & - & $\begin{array}{c}0.04 \\
(\mathrm{~W} / \mathrm{m} * \mathrm{~K})\end{array}$ & $\begin{array}{c}0.18 \\
(\mathrm{w} / \mathrm{m}-\mathrm{K})\end{array}$ & $23\left((\mathrm{~W} / \mathrm{m})^{*} \mathrm{~K}\right)$ \\
\hline $\begin{array}{l}\text { Thermal } \\
\text { resistance }\end{array}$ & - & $\begin{array}{c}1.8029 * 10^{-4} \\
\mathrm{~K} / \mathrm{w}\end{array}$ & $\begin{array}{c}4.0739 \\
\mathrm{~K} / \mathrm{W}\end{array}$ & $\begin{array}{l}1.8029 * 10^{-4} \mathrm{~K} / \mathrm{W} \\
\text { (with glass wool) }\end{array}$ \\
\hline At $1200^{\circ} \mathrm{C}$ & Tungsten & Glass wool & Hydrogen & Stainless steel \\
\hline $\begin{array}{c}\text { Specific heat } \\
\text { capacity }\end{array}$ & $\begin{array}{c}156 \\
\mathrm{~J} /(\mathrm{Kg}-\mathrm{K})\end{array}$ & - & $\begin{array}{c}15770 \\
(\mathrm{~J} /(\mathrm{Kg}-\mathrm{k}))\end{array}$ & - \\
\hline Heat capacity & $\begin{array}{c}21.2713 \\
(\mathrm{~J} / \mathrm{K})\end{array}$ & - & $\begin{array}{c}66.84903 \\
(\mathrm{~J} / \mathrm{K})\end{array}$ & - \\
\hline $\begin{array}{c}\text { Thermal } \\
\text { conductivity }\end{array}$ & - & $\begin{array}{c}0.04 \\
((\mathrm{~W} / \mathrm{m}) * \mathrm{~K})\end{array}$ & $\begin{array}{c}0.18 \\
(\mathrm{w} / \mathrm{m}-\mathrm{K})\end{array}$ & $\begin{array}{c}24 \\
((\mathrm{~W}-\mathrm{m}) * \mathrm{~K})\end{array}$ \\
\hline $\begin{array}{c}\text { Thermal } \\
\text { resistance }\end{array}$ & - & $\begin{array}{c}1.8029^{*} 10^{-4} \\
\mathrm{~K} / \mathrm{W}\end{array}$ & $\begin{array}{c}4.0739 \\
\mathrm{~K} / \mathrm{W}\end{array}$ & - \\
\hline
\end{tabular}
of about 100 or $150 \mathrm{~mm}$ thickness as illustrated in the Fig. 13.

TABLE II Value of Parameters At $900^{\circ} \mathrm{C} \& 1200^{\circ} \mathrm{C}$

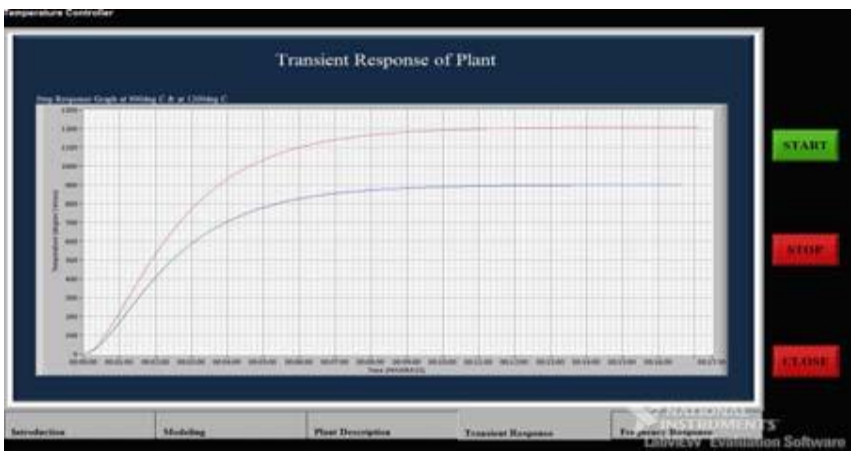

Fig. 10. Screen shot of transient response for temperature model

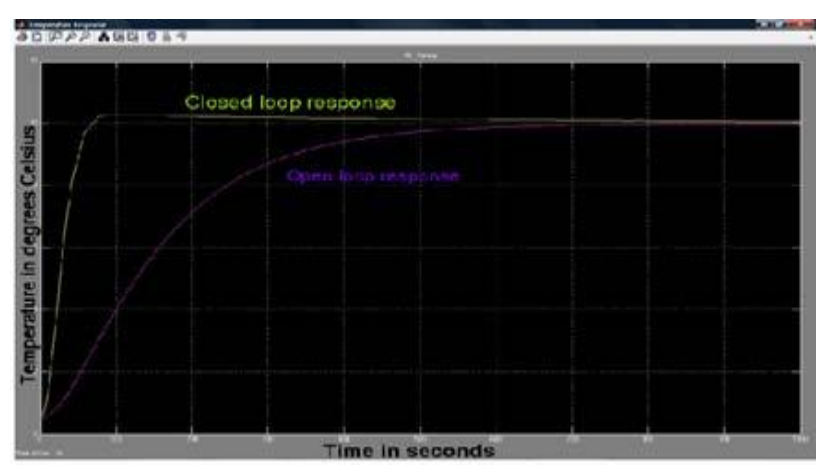

Fig. 11. Simulation of open $\&$ closed loop response of plant using MATLAB

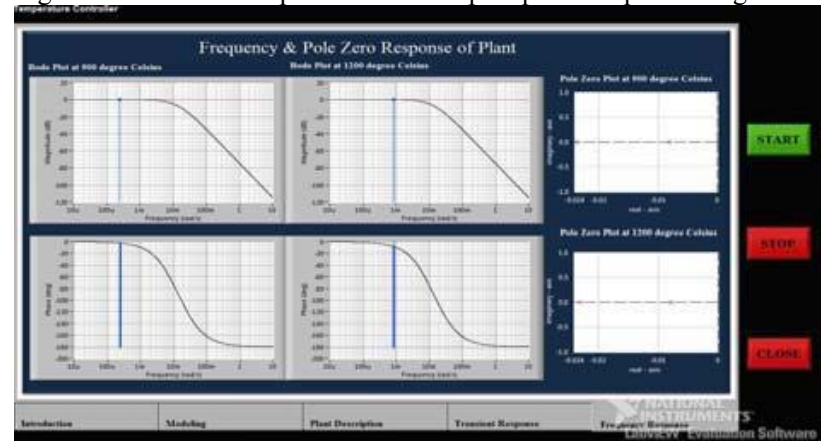

Fig. 12. Frequency response of the thermal plant

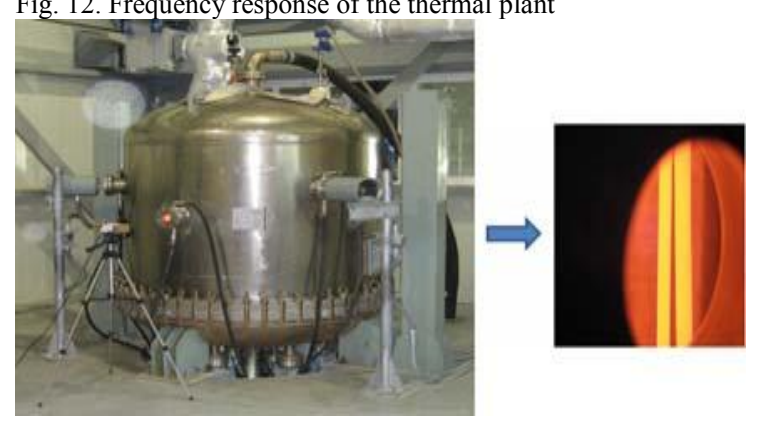

Fig. 13. Vision based Silicon Diameter Measurement

\section{CONCLUSION \& FUTURE WORK}

The proposed novelty to optimize the control of PVT parameters in a poly-silicon CVD reactor is designed, modeled and developed to achieve productivity of Poly-silicon seed at a high temperature of $1050^{\circ} \mathrm{C}-1100^{\circ} \mathrm{C}$. with It was observed that the process risk parameters of non-linear time variant CVD system are completely observable \& controllable. Also, it si observed that the system is highly stable at a temperature of $900^{\circ} \mathrm{C} \& 1200^{\circ} \mathrm{C}$ which is the worst cases for the seed growth. Specific heat capacity varies slightly from $150-156 \mathrm{~J}(\mathrm{Kg}-\mathrm{K})$ across $900-1200^{\circ} \mathrm{C}$. developing the PVT control model at such a high temperature is very difficult. Using NI LabVIEW, eased the construction of complex thermal structure and also saved time \& speed in acquiring response of complex reactor modules immensely. The result is a hazard \& risk resistant and reproducible system capable of producing poly-silicon ingot upto $10 \mathrm{~N}$ purity level via chemical route. The GUI based HMI is reliable to the user with Security \& Data management capacity and Emergency 
handling capability of a process by making the system compliant with the required industrial standards ensuring safety. HMI can also be facilitated with development of wireless remote and touch screen capabilities.

\section{ACKNOWLEDGMENT}

This work is sponsored by Sunlux Technologies Ltd., Bangalore. We would like to thank the group Manager, Mr. Abhinav A. Kalamdani, Management and staff of Photovoltaics and Controls group for the support of this work.

\section{VIII.REFERENCES}

[1] A.F.B. Braga, S.P. Moreira, P.R. Zampieri, J.M.G. Bacchin, P.R. Mei, "New processes for the production of solar-grade polycrystalline silicon: A review", ScienceDirect, Elsevier publishers, Solar Energy Materials \& Solar Cells, Volume 92, Issue 4, Apr. 2007, pp. 418-424.

[2] Brochures from Siemens, FabFocus, "Polysilicon Portfolio", Solar/ Semiconductor, 2008, pp. 14-15. Available:http://www.water.siemens.com/sitecollectionDocuments/Indu st ries/Electronics/Brochures/R4530_Poly-silic_S1415.pdf

[3] Brochures and reports from Research and Markets, "Solar Polysilicon Industry Report", 2007-2008.

Available:

http://www.researchandmarkets.com/reports/599721/Solar

Polysilicon Industry Report, 2007-2008

[4] Brochures from Sageconcept, "Report II Polysilicon 2008 Summary", Executives summary, 2008, pp.16-20.

Available: http://www.sageconceptsonline.com/docs/report2.pdf

[5] F. Teyssandier and A. Dollet, "Chemical vapor deposition", ScienceDirect, Elsevier publishers, Pergamon Materials Series, Volume 2, Mar. 1999, pp. 257-285.

[6] K. L. Choy, "Chemical vapour deposition of coatings", ScienceDirect, Elsevier publishers, Progress in Materials Science, Volume 48, Issue 2, Mar. 2003, pp. 57-170.

[7] Copyright of Sunlux Technologies Limited (Address: Regd. Office \& H.O.: 60-61, $1^{\text {st }}$ Floor, Balaji Mansion, Dr. Rajkumar Road, Prakashnagar, Bangalore - 560021, India, Ph: + 91080 65954374/ 23322425,email:info@sunlux-india.com \& abhinav.k@sunluxindia.com)

[8] Abhinav A. Kalamdhani, "Production of silicon grade silicon-A control perspective" presented at ISA Bangalore Section, April 2009, Slide No. $<5,[7,8,[12,13,14,25,29>$

[9] Richard C. Dorf, Editor-in-chief, "The Engineering Handbook", A CRC Press Handbook Published in Cooperation with IEEE Press, CRC press catalog number 8344, 2000, pp. 1897- 1907 and pp. 1767-1777.

[10] Curtis D.Johnson, "Process Control Instrumentation Technology",
Eighth Edition, Prentice Hall of India(PHI), 2008, pp. 33,619.

[11] Paris Stavrianidis, Kumar Bhimavarapu, "Safety Instrumented Functions and Safety Integrity Levels(SIL)", Risk Engineering Methodologies, ISA Transactions 37, Elsevier Science Ltd ,1998, pp. 337-351.

[12] Surekha Bhanot, "Process Control Principle And Applications", Oxford University Press, 2008, pp. 207- 209

[13] SEMI(Semiconductor Equipment and Materials International), SEMI S22-0706a, "Safety guideline for the electrical design of semiconductor Manufacturing Equipment", (Reapproved 0307), 2006.

[14] SEMI(Semiconductor Equipment and Materials International), SEMI E95-1101, "Specification For Human Interface For Semiconductor Manufacturing Equipment”, (Reapproved 0307), 2007.

[15] Michael Quirk and Julian Serda, "Semiconductor Manufacturing Technology", Instructor's Manual, Prentice Hall. Available: http://www.smtbook.com/instructor guide.pdf

[16] G.C.Garg, "Utilization of Electric power \& Electric traction", Eight Edition, Khanna publishers, Delhi, 2005, pp. 712-814

[17] Dale E.Seborg, Thomas.F.Edger, Duncan A.Mellichamp, "Process dynamics and control", Second edition, Wiley India edition(WSE), 2008, pp. 248-254.

[18] Data manuals collected from National Instrument's, National Instruments, 2008. Available: http://www.ni.com/LabVIEW

[13] Information from Vacuum guide. Available: http://www.vacuumguide.com / english / equipment / evacuation_time vacuum_pump sizing.html

[14] J P Holman adapted by souvik Bhattacharyya, "Heat Transfer"(in SI Units), Ninth edition, Mc.Graw Hill companies, Special Indian Edition (SiE), 2007, pp. 25-33

[15] John H.Lienhard IV and John H.Lienhard V, "A Heat Transfer Textbook", Third Edition, Phlogiston Press, Cambridge Massachusetts, 2008, pp.49-127.

[16] Katsuhiko ogata, "Discrete-Time Control System", Second Edition, Low Price Pearson Edition, 2008, pp. 293-320.

[17] Jacek Korec, "A general model of the chemical vapour deposition process I: Theory", ScienceDirect, Elsevier publishers, Surface Technology, Volume 10, Issue 6, June 1980, pp. 433-454.

[18] Meng Tao, "Growth kinetics and reaction mechanism of silicon chemical vapour deposition from silane", ScienceDirect, Elsevier publishers, Thin Solid Films, Volume 223, Issue 2, Feb. 1993, pp. 201211.

[19] M.L.Hitchman, J.Kane and A.E.Widmer, "Polysilicon growth kinetics in a low pressure chemical vapour deposition reactor", ScienceDirect, Elsevier publishers, Thin Solid Films, Volume 59, Issue 2, Aug. 2002, pp.231-247.

[20] L. Bu, H. Hu, C. Bevan, M. Wang, S. Sanchez, E. Luo, "Investigation of polycrystalline silicon grain structure with single wafer chemical vapor deposition technique", IEEE Trans., Journal of Vacuum Science \& Technology A: Vacuum, Surfaces, and Films, Volume 19, Issue 4, Jul. 2001, pp. 1898-1901. 